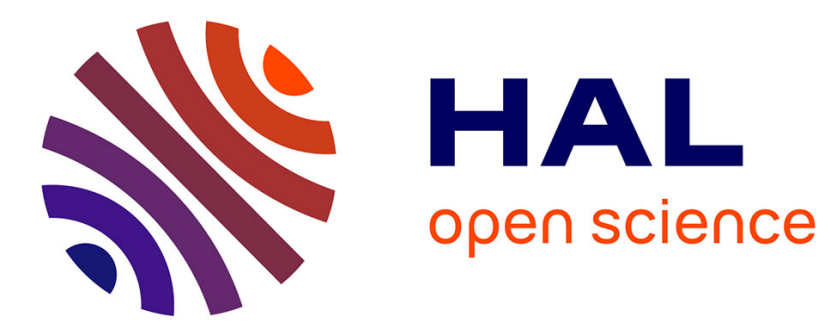

\title{
Experimental investigation and thermodynamic modeling of molybdenum and vanadium-containing carbide hardened iron-based alloys
}

Elodie Cabrol, Cédric Bellot, Pascal Lamesle, Denis Delagnes, E. Povoden-Karadeniz

\section{To cite this version:}

Elodie Cabrol, Cédric Bellot, Pascal Lamesle, Denis Delagnes, E. Povoden-Karadeniz. Experimental investigation and thermodynamic modeling of molybdenum and vanadium-containing carbide hardened iron-based alloys. Journal of Alloys and Compounds, 2013, 556, pp.203-209. 10.1016/j.jallcom.2012.12.119 . hal-01687317

\section{HAL Id: hal-01687317 https://hal.science/hal-01687317}

Submitted on 15 Mar 2019

HAL is a multi-disciplinary open access archive for the deposit and dissemination of scientific research documents, whether they are published or not. The documents may come from teaching and research institutions in France or abroad, or from public or private research centers.
L'archive ouverte pluridisciplinaire $\mathbf{H A L}$, est destinée au dépôt et à la diffusion de documents scientifiques de niveau recherche, publiés ou non, émanant des établissements d'enseignement et de recherche français ou étrangers, des laboratoires publics ou privés. 


\title{
Experimental investigation and thermodynamic modeling of molybdenum and vanadium-containing carbide hardened iron-based alloys
}

\author{
E. Cabrol ${ }^{\mathrm{a}, \mathrm{b}, *}$, C. Bellot ${ }^{\mathrm{a}, \mathrm{b}}$, P. Lamesle ${ }^{\mathrm{a}}$, D. Delagnes ${ }^{\mathrm{a}}$, E. Povoden-Karadeniz ${ }^{\mathrm{c}}$ \\ ${ }^{a}$ Institut Clément Ader, Mines Albi, Campus Jarlard, F-81013 Albi Cedex 09, France \\ ${ }^{\mathrm{b}}$ Aubert \&' Duval, BP1 F-63770 Les Ancizes, France

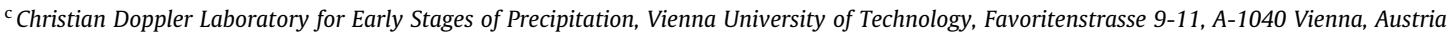

\begin{abstract}
A B S T R A C T
A technique for the microstructural study of steels, based on the use of matrix dissolution to collect the very low number density precipitates formed in martensitic steels, has been considerably improved. This technique was applied to two different grades of alloy, characterized by high nickel and cobalt contents and varying chromium, molybdenum and vanadium contents. The technique was implemented at temperatures ranging between $900{ }^{\circ} \mathrm{C}$ and $1000{ }^{\circ} \mathrm{C}$, in order to accurately determine experimental data including the crystallographic structure and chemical composition of the carbides, the carbide solvus temperatures, and variations in the chemical composition of the matrix. These experimental investigations reveal that the solubility of molybdenum in FCC carbides can be very high. These results have been compared with the behavior predicted by computational thermodynamics, and used to evaluate and improve the thermodynamic Matcalc steel database. This upgraded database has been validated on three other steels with different chemical compositions, characterized by the same $\mathrm{Fe}-\mathrm{Cr}-\mathrm{Mo}-\mathrm{V}-\mathrm{C}$ system.
\end{abstract}

Keywords:

Metals and alloys

Precipitation

Phase diagrams

X-ray diffraction

\section{Introduction}

Complex heat treatments are often applied to martensitic steels, to obtain the required mechanical properties, in particular yield stress or fracture toughness. As widely described in the literature, these properties and the service life of martensitic steels, are closely related not only to the chemical composition and crystallographic structure of the precipitates formed during tempering, but also to the presence of undissolved carbides during austenitization [1-4]. These precipitates are needed to control austenitic grain growth $[4,5]$. However, at too low austenitizing temperatures, significant quantities of undissolved carbides remain in the matrix, resulting in a reduction of the steel's crack propagation resistance [6-10]. The highest possible proportion of these carbides and associated chemical elements must therefore be dissolved, in order to avoid this effect and to promote the nucleation of secondary nano-scale precipitates during subsequent tempering [11,12].

Various analytical advanced techniques such as transmission electron microscopy (TEM), atom probe tomography (APT) or small angle neutron scattering (SANS) can be applied to the study of precipitates. However, in the present case, these techniques are not

\footnotetext{
* Corresponding author at: Ecole des Mines d'Albi-Carmaux, Campus Jarlard, Route de Teillet, F-81013 Albi Cedex 09, France. Tel.: +33 (0)5 634931 05; fax: +33 (0)5 63493242 .

E-mail address: ecabrol@mines-albi.fr (E. Cabrol).
}

entirely suitable for the accurate quantification of precipitation into the bulk material, due to the very low quantity of precipitates present in the matrix during austenitization. Moreover, except for a very limited volume (few $\mathrm{nm}^{3}$ ), the matrix composition cannot be determined at the austenitizing temperature using these techniques. This is a considerable drawback for the different precipitation stages, since the austenite composition has a direct influence on the secondary nanometric precipitation produced by tempering. In order to study the scattered precipitates present in a given matrix, several authors have developed chemical or electrochemical extraction methods, followed by filtration or centrifugation. Using these techniques, the precipitation of titanium and niobium carbonitrides in micro-alloyed steels [13], and the precipitation of carbides during tempering in hot-work tool steels [11-14] and ultra-high-strength steels [15] have been studied. However, no study has been made of the chemical composition of the matrix components during austenitization. In practice, very high performance techniques are needed to analyze the changes in concentration which occur in alloying elements during austenitization.

The main goal of the present study is to provide experimental results related to the crystallographic structures and chemical composition of carbides, as well as to variations in chemical composition of the matrix at temperatures above $900^{\circ} \mathrm{C}$, for two martensitic grades of steel. For this purpose, extraction methods were adapted to the study of very low density precipitates and very low changes in atomic fraction. 
In the second part of this study, the experimental results have been used to evaluate and adjust the thermodynamic Matcalc steel databases [16] for applied austenitization computations. The upgraded database was thus validated for three other types of steel with different chemical compositions in the same multicomponent chemical system.

\section{Materials and experimental method}

\subsection{Investigated steels}

Two different grades (MoV and MoMoV) of steel, with a high nickel and cobal content and differing chromium, molybdenum and vanadium contents were studied. The nominal compositions of these alloys, in atomic percent, are provided in Table 1.

The heat treatment involves austenitizing for $1 \mathrm{~h}$, followed by air quenching. The austenitizing temperatures studied for each steel grade were $900{ }^{\circ} \mathrm{C}, 925^{\circ} \mathrm{C}$, $950^{\circ} \mathrm{C}$ and $975^{\circ} \mathrm{C}$. In [17], Epp et al. have determined the carbide volume fraction and the austenite lattice parameter, as a function of the austenitizing time, at four different temperatures. In this study [17], it was shown that the carbides came very close to thermodynamic equilibrium after $1 \mathrm{~h}$ of treatment.

\subsection{Experimental method}

In this section, a description is given of the experimental method used to study the precipitates. The diagram provided in Fig. 1 outlines the experimental steps, starting with chemical dissolution of the matrix by means of centrifugation, and ending with the use of various analysis techniques allowing the size, morphology and chemical compositions of the precipitates to be determined.

\subsubsection{Precipitate extraction}

The carbides and/or nitrides were extracted by chemical dissolution of the matrix, in a modified Berzelius solution at room temperature [18]. Several authors have used this method to study titanium and niobium carbonitrides in micro-alloyed steels [13], or carbide precipitation during tempering in hot-work tool steels [11-14] and ultra-high-strength steel [15]. In the present case, a 20 g sample was dissolved in a $500 \mathrm{ml}$ modified Berzelius solution. After dissolution, the solution was centrifuged for 40 min by a Beckman Coulter Avanti J-30I centrifugal machine equipped with a JA-30.50Ti rotor. With this machine, the solution is subjected to a radial acceleration of approximately $110000 \mathrm{~g}$, leading to the extraction of nanoscale precipitates. The resulting powder was dried for $12 \mathrm{~h}$.

\subsubsection{X-ray diffraction (XRD) analyses}

The crystallographic structure of the precipitates was determined by XRD, using a Panalytical X'Pert PRO diffractometer equipped with a $\mathrm{Cu}$ radiation source $(\lambda K \alpha=0.154 \mathrm{~nm})$ and a diffracted beam monochromator to avoid iron fluorescence. Phase identification was achieved by comparing the diffraction pattern of the experimental powders with reference JCPDS patterns.

2.2.3. Inductively Coupled Plasma Optical Emission Spectrometry (ICP-OES) analyses

The chemical compositions of the carbides and the matrix were determined by ICP-OES.

The powders collected following centrifugation were chemically mineralized for the purpose of these analyses. Standard ranges, including 8 multicomponent solutions, were prepared in order to cover the expected carbide element fraction of each alloying element.

The solutions collected after centrifugation were totally free of precipitates, and the same experimental setup was used to evaluate the chemical composition of the matrices.

\section{Experimental results}

\subsection{Crystallographic structures of the precipitates}

The crystallographic structures of the precipitates was determined using XRD, following chemical extraction and centrifuga-

Table 1

Chemical composition of the studied steels (at.\%).

\begin{tabular}{llllllll}
\hline & $\mathrm{C}$ & $\mathrm{Cr}$ & $\mathrm{Mo}$ & $\mathrm{V}$ & $\mathrm{Ni}$ & $\mathrm{Co}$ & $\mathrm{Al}$ \\
\hline MoV-alloyed & 0.93 & 2.56 & 0.42 & 0.33 & 13.21 & 9.46 & 1.84 \\
MoMoV-alloyed & 1.05 & 3.55 & 0.86 & 0.27 & 12.20 & 5.38 & 3.47 \\
\hline
\end{tabular}

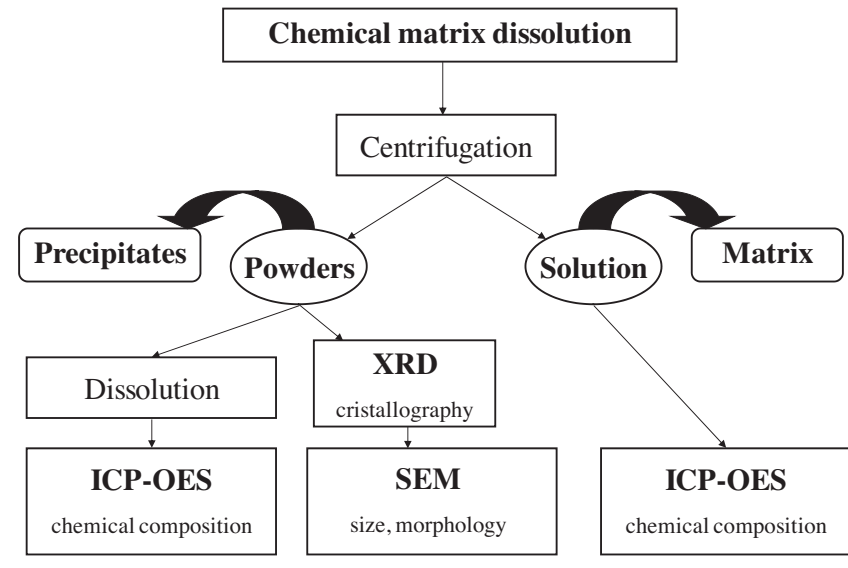

Fig. 1. Flow chart of the experimental method.

tion. The lattice parameter accuracy was $1.1 \mathrm{pm}(0.6 \mathrm{pm}$ for the experimental accuracy, and $0.5 \mathrm{pm}$ for the instrumental accuracy).

\subsubsection{MoV-alloyed steel}

Fig. 2 shows the XRD profiles of the precipitates extracted from the MoV-alloyed steel after austenitizing at 900,925 and $950{ }^{\circ} \mathrm{C}$. At $975^{\circ} \mathrm{C}$, no carbides could be detected. All of the peaks shown in these spectra can be indexed in accordance with a face-centered cubic structure. The lattice parameter was determined to be $0.416 \mathrm{~nm}$. The structure and lattice parameter of the extracted cubic carbide are very similar to the $\mathrm{V}_{4} \mathrm{C}_{3}$ structure described in the JCPDS pattern 1-1159 (quality blank), and to the $\mathrm{MoC}_{0.5}$ structure described in the JCPDS pattern 15-457 (quality blank). These two structures have the same space group $(\mathrm{Fm} 3 \mathrm{~m}$ ) and almost the same lattice parameter (respectively $0.4160 \mathrm{~nm}$ and $0.4155 \mathrm{~nm}$ ).

\subsubsection{MoMoV-alloyed steel}

The XRD profiles of the precipitates extracted from the MoMoValloyed steel are shown in Fig. 3 for each studied temperature. At $900{ }^{\circ} \mathrm{C}$, two different carbides were indexed: orthorhombic $\mathrm{Cr}_{7} \mathrm{C}_{3}$ carbides (JCPDS pattern 36-1482, quality star), and face-centered cubic $\mathrm{V}_{4} \mathrm{C}_{3}$ (JCPDS pattern 1-1159) or $\mathrm{MoC}_{0.5}$ (JCPDS pattern 15457) carbides. Above $925^{\circ} \mathrm{C}$, only face-centered cubic carbides were detected. The solvus temperature of the $\mathrm{Cr}_{7} \mathrm{C}_{3}$ carbides thus ranges between 900 and $925^{\circ} \mathrm{C}$. The lattice parameters measured for the $\mathrm{Cr}_{7} \mathrm{C}_{3}$ carbides were $a=0.717 \mathrm{~nm}, b=1.215 \mathrm{~nm}$ and $c=0.450 \mathrm{~nm}$ and the lattice parameters measured for the face-centered cubic structures ranged between $0.416 \mathrm{~nm}\left(950\right.$ and $\left.975{ }^{\circ} \mathrm{C}\right)$ and $0.419 \mathrm{~nm}\left(900\right.$ and $925^{\circ} \mathrm{C}$ ). These lattice parameters are very close to the JCPDS patterns of both $\mathrm{MoC}_{0.5}$ and $\mathrm{V}_{4} \mathrm{C}_{3}$.

\subsubsection{Discussion}

With the exception of the orthorhombic $\mathrm{Cr}_{7} \mathrm{C}_{3}$ carbides indexed in the MoMoV-alloyed steel, after $1 \mathrm{~h}$ of heat treatment at $900{ }^{\circ} \mathrm{C}$, the face-centered cubic carbides were indexed with very close lattice parameters for all studied temperatures for the investigated steels. However, changes in the peak' intensities are know to be related to a change in the carbide's chemical composition and/or carbon under-stoichiometry.

In the case of MoV-alloyed steels, the carbides are very close to the $\mathrm{V}_{4} \mathrm{C}_{3}$ carbides described in the JCPDS pattern 1-1159, and the most intense peak corresponds to the (200) plane, whereas the carbides extracted from the MoMoV-alloyed steel are closer to the $\mathrm{MoC}_{0.5}$ carbides described in the JCPDS pattern 15-457. Moreover, the most intense peak corresponds to the (111) plane (Table 2). From these results, two different types of cubic carbide appear to be present in each steel. 


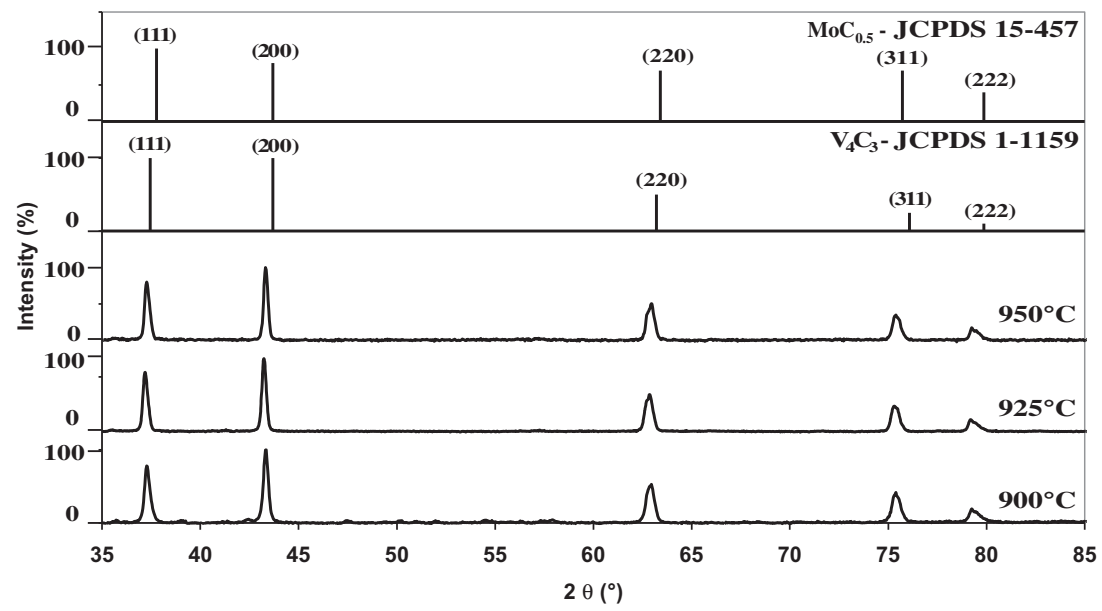

Fig. 2. Reference JCPDS patterns and XRD profiles (relative intensities) of precipitates extracted from the MoV-alloyed steel.

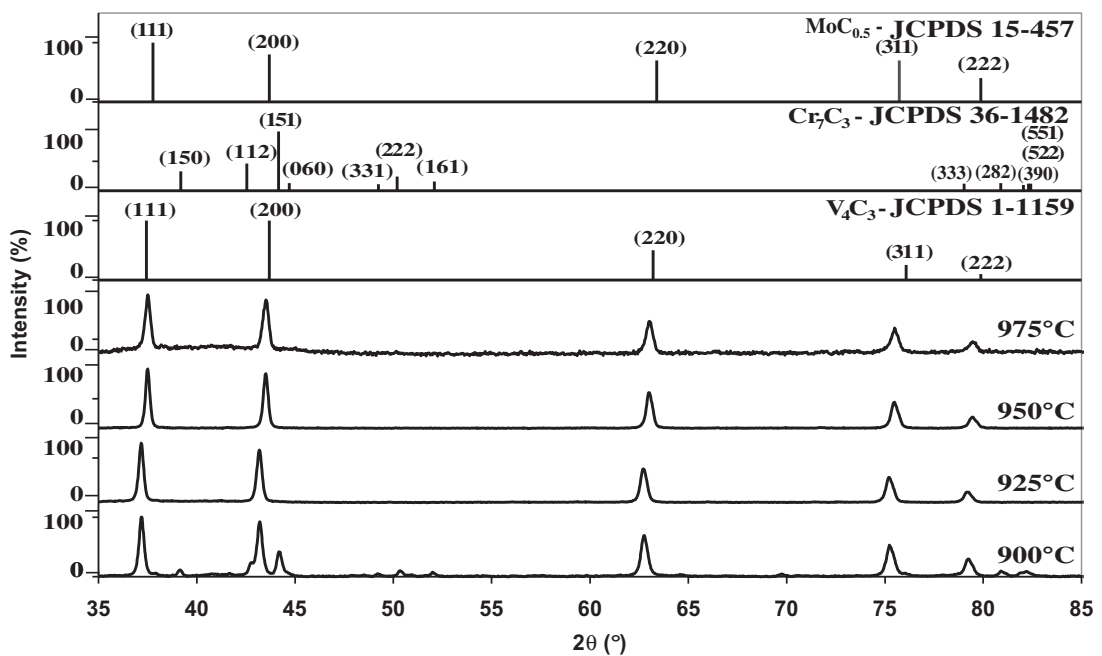

Fig. 3. Reference JCPDS patterns and XRD profiles (relative intensities) of precipitates extracted from the MoMoV-alloyed steel.

Table 2

Average relative intensities for the three steels and JCPDS patterns.

\begin{tabular}{llllll}
\hline & $(111)$ & $(200)$ & $(220)$ & $(311)$ & $(222)$ \\
\hline MoMoV-alloyed & 100 & 91.2 & 60.2 & 45.7 & 19 \\
MoV-alloyed & 79.7 & 100 & 51.4 & 37.2 & 17.7 \\
$\mathrm{~V}_{4} \mathrm{C}_{3}$ JCPDS 1-1159 & 100 & 100 & 50 & 25 & 10 \\
$\mathrm{MoC}_{0.5}$ JCPDS 15-457 & 100 & 80 & 70 & 70 & 40 \\
\hline
\end{tabular}

\subsection{Chemical composition}

In order to better understand the microstructural evolution of the different grades of steels during austenitization, and to confirm the presence (or absence) of two different types of cubic carbide, variations in the chemical composition of the solution were determined after centrifugation, and the extracted carbides were measured and correlated with the XRD results.

In the matrix, the $\mathrm{Ni}, \mathrm{Co}, \mathrm{Al}$ and $\mathrm{Fe}$ contents remain constant and close to the nominal contents for both MoV- and MoMoValloyed grades, at all of the studied temperatures. The trends determined for the Mo, $\mathrm{Cr}$ and $\mathrm{V}$ are described in the following section.

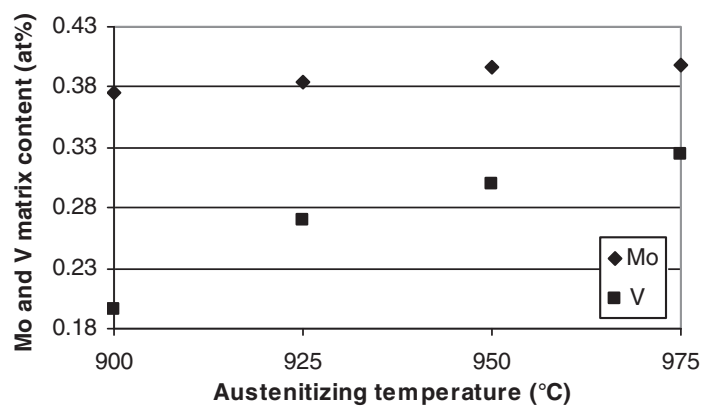

Fig. 4. Mo and $\mathrm{V}$ contents in the MoV-alloyed matrix at four different austenitizing temperatures (at.\%).

\subsubsection{MoV-alloyed steel}

The chromium content remains constant at all austenitizing temperatures and is close to the nominal chromium content of the steel. This result is consistent with the XRD results, which indicate that there could be a lack of chromium in the cubic carbides. The molybdenum and vanadium contents in the matrix of the MoV-alloyed steel are shown in Fig. 4. 
Table 3

V/Mo ratio for carbides extracted from MoV-alloyed steel.

\begin{tabular}{cc}
\hline & V/Mo \\
\hline $900{ }^{\circ} \mathrm{C}$ & 6.2 \\
$925^{\circ} \mathrm{C}$ & 6.9 \\
$950^{\circ} \mathrm{C}$ & 26.3 \\
\hline
\end{tabular}

The molybdenum and vanadium contents are seen to increase when the temperature is increased, which supports the theory of dissolution of the $(\mathrm{V}, \mathrm{Mo}) \mathrm{C}$ carbides. At $900{ }^{\circ} \mathrm{C}$, the difference between the nominal and analyzed contents is more pronounced for vanadium than for molybdenum, suggesting that the carbides are more strongly enriched in vanadium than in molybdenum. Between 950 and $975^{\circ} \mathrm{C}$, the molybdenum content remains constant. It is thus likely that the molybdenum is completely dissolved in the matrix at temperatures above $950{ }^{\circ} \mathrm{C}$. At $975^{\circ} \mathrm{C}$, the molybdenum and vanadium contents in the matrix are close to the steel's nominal composition, such that the $(\mathrm{V}, \mathrm{Mo}) \mathrm{C}$ carbides dissolve into the matrix. This result confirms our XRD measurements: no carbide patterns are detected at $975^{\circ} \mathrm{C}$.

The chemical compositions of the carbides obtained at each studied temperature show that between 900 and $950{ }^{\circ} \mathrm{C}, \mathrm{MoV}$-alloyed steel carbides contain essentially vanadium (and iron), but also a small quantity of molybdenum. However, the carbides are practically molybdenum-free at $950{ }^{\circ} \mathrm{C}$. The ratio between the vanadium and molybdenum contents (at.\%), determined by ICPOES analysis, increases as a function of temperature, as shown in Table 3.

\subsubsection{MoMoV-alloyed steel}

In the case of the MoMoV-alloyed steel, the molybdenum and vanadium contents in the matrix increased with increasing austenitizing temperature and higher levels of carbide dissolution (Fig. 5).

Between 925 and $975^{\circ} \mathrm{C}$, the chromium content in the matrix remains constant and close to the steel's nominal composition, whereas a decrease is observed between 925 and $900{ }^{\circ} \mathrm{C}$, from 3.54 at.\% to 3.40 at.\%. This result is consistent with the XRD results since the $\mathrm{Cr}_{7} \mathrm{C}_{3}$ carbides were indexed after austenitizing at $900{ }^{\circ} \mathrm{C}$. The difference between the nominal and analyzed contents was similar for the vanadium and the molybdenum. The carbides were thus more strongly enriched in molybdenum than those observed in the MoV-alloyed steel.

As described in Section 3.1.2, at $900{ }^{\circ} \mathrm{C}$, two different types of carbide could be detected: $\mathrm{Cr}_{7} \mathrm{C}_{3}$ and cubic (V,Mo)C. This result is in agreement with the chemical analyses of the carbides, since the ICP-OES measurements (Table 4) indicate that all of the corresponding metallic elements (chromium, molybdenum, vanadium

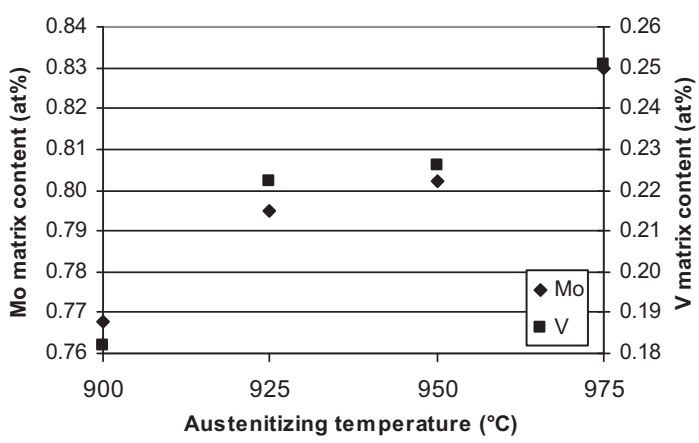

Fig. 5. Mo and V contents in MoMoV-alloyed matrices at four different austenitizing temperatures (at.\%).
Table 4

Chemical composition (at.\%) of metallic elements in the carbides extracted from the MoMoV-alloyed steel after austenitizing at $900{ }^{\circ} \mathrm{C}$.

\begin{tabular}{llll}
\hline $\mathrm{Cr}$ & Mo & $\mathrm{V}$ & $\mathrm{Fe}$ \\
\hline 27.14 & 20.67 & 37.27 & 14.91 \\
\hline
\end{tabular}

Table 5

V/Mo ratio for carbides extracted

from MoMoV-alloyed steel.

\begin{tabular}{ll}
\hline & V/Mo \\
\hline $900{ }^{\circ} \mathrm{C}$ & 1.8 \\
$925^{\circ} \mathrm{C}$ & 1.6 \\
$950^{\circ} \mathrm{C}$ & 0.5 \\
$975{ }^{\circ} \mathrm{C}$ & 0 \\
\hline
\end{tabular}

and iron) were present in the particles. From $925^{\circ} \mathrm{C}$ to $975^{\circ} \mathrm{C}$, where only the face-centered cubic carbides are indexed, the carbides are vanadium- and molybdenum-enriched. The molybdenum content is greater than 30 at.\%, which is an unusually high value for cubic carbides. Serna [19] had already observed this type of molybdenum-rich face-centered cubic carbide in an M2 high-speed steel with a very different chemical composition.

Contrary to the MoV-alloyed steel, in the MoMoV steel, the ratio between the vanadium and molybdenum contents decreases with temperature (Table 5). Furthermore, this ratio is considerably lower in this steel than in the MoV-alloyed steel. The measured variations in this ratio as a function of temperature are in agreement with the other experimental results (XRD and chemical composition variations of the matrix).

\subsubsection{Discussion}

XRD experiments have revealed two different behaviors for the peak intensities of cubic carbides extracted from MoV or MoMoValloyed steels. The chemical compositions of the matrix and carbides have confirmed this difference. The observed variations in carbide characteristics with increasing Mo-content in the matrix was unexpected. Although cubic carbides are only slightly enriched in molybdenum, in the case of MoV-alloyed steels, the molybdenum content is considerably higher in MoMoV-alloyed steel. Moreover, the structure of the carbides is the cubic MC type, and not the hexagonal $\mathrm{M}_{2} \mathrm{C}$ or cubic $\mathrm{M}_{6} \mathrm{C}$ type as generally reported in the literature [20-22]. Furthermore, close to the carbide solvus temperatures, two different evolutions are observed: in the case of MoV-alloyed steel, a low molybdenum content is measured in vanadium-rich MC type carbides, whereas in MoMoV-alloyed steel the situation is exactly the opposite and the carbides are totally free of vanadium at an austenitizing temperature of $975^{\circ} \mathrm{C}$.

These different elements confirm the presence of two different cubic carbides: $\mathrm{V}_{4} \mathrm{C}_{3}$ in MoV-alloyed steel and $\mathrm{MoC}_{0.5}$ in MoMoValloyed steel. From first-principles calculations, Jang et al. [23] demonstrated that the consequence of improved stability of MoC cubic carbides was carbon under-stoichiometry leading to the subsequent $\mathrm{MoC}_{0.5}$ composition.

These structures have the same space group (Fm3m) and almost the same lattice parameter (respectively $0.4160 \mathrm{~nm}$ and $0.4155 \mathrm{~nm}$ ). Although the molybdenum atom is greater in size than that of vanadium, this difference is compensated by an increase in carbon under-stoichiometry. Fig. 6 plots the carbide carbon content, as a function of the carbides' molybenum and vanadium contents.

\section{Thermodynamic calculations}

Calculations were performed for the two alloys, using version 5.44.1012 of the Matcalc software and the following databases: 


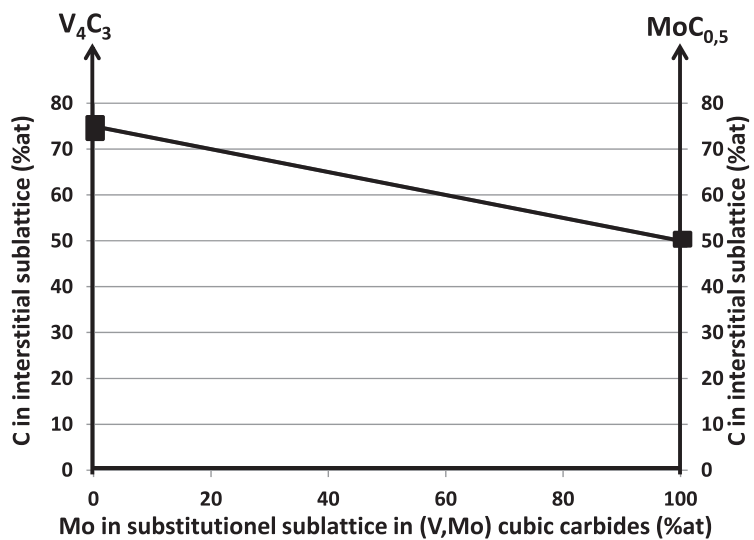

Fig. 6. Calculated variation in carbon content in cubic carbides, as a function of their molybdenum and vanadium contents.

firstly, the mc_steel_1.50 database, state of the art prior to the present study and successfully used in thermo-kinetic precipitation simulations in steel [24], was tested. The experimental results described in the study were then used to optimize the model parameters of the $\mathrm{Fe}-\mathrm{Cr}-\mathrm{Mo}-\mathrm{V}-\mathrm{C}$ subsystem, resulting in an upgraded mc_fe_v1.028 database.

For each type of steel, the thermodynamic calculations were performed using the chemical compositions presented in part 2.1 (Table 1) of this paper. The following quantities were computed:

- the carbides' crystallographic structures between $900{ }^{\circ} \mathrm{C}$ and $1000^{\circ} \mathrm{C}$,

- the variations in the matrix's chemical composition, between $900{ }^{\circ} \mathrm{C}$ and $1100{ }^{\circ} \mathrm{C}$,

- the variations in the carbides' chemical composition, between $900{ }^{\circ} \mathrm{C}$ and the solvus temperature.

\subsection{Crystallographic structures and solvus of the carbides}

Table 6 lists the types of carbides obtained from the Matcalc calculations between 900 and $975^{\circ} \mathrm{C}$, for each steel, using the two databases. Basically, in mc_fe_v1.028, the fcc-structure is stabilized relative to hcp. Thus, for MoV-alloyed steel, the fcc-type is predicted when either database is used. For the MoMoV-alloyed steel, the optimized database correctly proposes the presence of cubic MC carbides.

Futhermore, with the optimization of the thermodynamic parameters, the predicted solvus temperatures decrease significantly, and are found to be close to the experimental results, as shown in Table 6.

\subsection{Chemical composition}

\subsubsection{MoV-alloyed steel}

When compared with the mc_steel_1.50 database, the optimized mc_fe_v1.028 database indicates a decrease in carbide solvus temperature, in agreement with the chemical composition variations observed in the matrix. This database predicts variations in the vanadium and molybdenum matrix content, which are in good agreement with the experimental results (Fig. 7).

\subsubsection{MoMoV-alloyed steel}

The mc_fe_v1.028 database also predicts a decrease in the carbide solvus temperature, in the case of the MoMoV-alloyed steel. The vanadium and molybdenum contents computed for the matrix are in good agreement with the experimental results (Fig. 8). Using the new mc_fe_v1.028 database, the molybdenum matrix content is lower than that computed for mc_steel_1.50. This outcome is associated with stable fcc MC carbides, rather than hexagonal $\mathrm{M}_{2} \mathrm{C}$ carbides.

The computed carbide molybdenum contents are given in Table 7. In the case of the MoV-alloyed steel, the mc_fe_v1.028 database provides a lower molybdenum content in the MC cubic carbides. In the case of the MoMoV-alloyed steel, the expected molybdenum content is lower with the mc_fe_v1.028 database due to the predicted presence of MC cubic carbides whereas for the mc_steel_1.50, the precipitation of $\mathrm{M}_{2} \mathrm{C}$ hexagonal carbides is predicted.

\subsection{Discussion}

When the database is optimized on the basis of the experimental results presented in this paper, a good agreement is found between the experimental and calculated results, in particular for the changes in the chemical composition of the matrix, and for the associated evolution of the MC carbide precipitates.

Different types of carbide have been determined qualitatively, through the use of simulations. One exception was observed, i.e. the observed stability of $\mathrm{Cr}_{7} \mathrm{C}_{3}$ in MoMoV-alloyed steel after austenitization at $900{ }^{\circ} \mathrm{C}$. As shown in the phase fraction vs. temperature plot obtained with the mc_fe_v1.028 database, fcc is the only thermodynamically stable type of carbide predicted for both studied steels under the austenitization conditions considered in the present study (Fig. 9).

Although the thermodynamic solvus temperature of $\mathrm{M}_{7} \mathrm{C}_{3}$ in MoMoV-alloyed steel is approximately $90{ }^{\circ} \mathrm{C}$ higher than that observed in MoV-alloyed, $\mathrm{M}_{7} \mathrm{C}_{3}$ remains metastable at $900{ }^{\circ} \mathrm{C}$ and, once formed, should dissolve after sufficient annealing time. It is assumed that $1 \mathrm{~h}$ of austenitizing is sufficient to obtain a closeto-equilibrium state [16]. However, this may not be true for phases with a large unit cell, such as $M_{7} C_{3}$. Thus, with the exception of some minor adjustments to the interaction parameter, the thermodynamic model parameters of $\mathrm{M}_{7} \mathrm{C}_{3}$ have not been substantially reoptimized, until such time as it can be determined whether $\mathrm{M}_{7} \mathrm{C}_{3}$ dissolves or remains stable after long-term annealing at $900{ }^{\circ} \mathrm{C}$.

\subsection{Validation}

In order to validate the modifications made to the thermodynamic mc_fe_v1.028 database using steels previously studied for their $\mathrm{Fe}-\mathrm{Cr}-\mathrm{Mo}-\mathrm{V}-\mathrm{C}$ subsytem, three different steels based on

Table 6

Comparison of carbide crystallographic structures and solvus temperatures calculated using two databases for the investigated steels.

\begin{tabular}{|c|c|c|c|c|c|c|}
\hline & & $900\left({ }^{\circ} \mathrm{C}\right)$ & $925\left({ }^{\circ} \mathrm{C}\right)$ & $950\left({ }^{\circ} \mathrm{C}\right)$ & $975\left({ }^{\circ} \mathrm{C}\right)$ & Solvus temperature $\left({ }^{\circ} \mathrm{C}\right)$ \\
\hline \multirow[t]{3}{*}{$\mathrm{MoV}$} & mc_steel_1.50 & FCC-MC & FCC-MC & FCC-MC & FCC-MC & 1020 \\
\hline & mc_fe_v1.028 & FCC-MC & FCC-MC & FCC-MC & & 952 \\
\hline & Experimental & FCC-MC & FCC-MC & FCC-MC & & $950-975$ \\
\hline \multirow[t]{3}{*}{ MoMoV } & mc_steel_1.50 & $\mathrm{HCP}-\mathrm{M}_{2} \mathrm{C}$ & $\mathrm{HCP}-\mathrm{M}_{2} \mathrm{C}$ & $\mathrm{HCP}-\mathrm{M}_{2} \mathrm{C}$ & $\mathrm{HCP}-\mathrm{M}_{2} \mathrm{C}$ & 1051 \\
\hline & mc_fe_v1.028 & FCC-MC & FCC-MC & FCC-MC & & 967 \\
\hline & Experimental & FCC-MC & FCC-MC & FCC-MC & FCC-MC & $975-1000$ \\
\hline
\end{tabular}




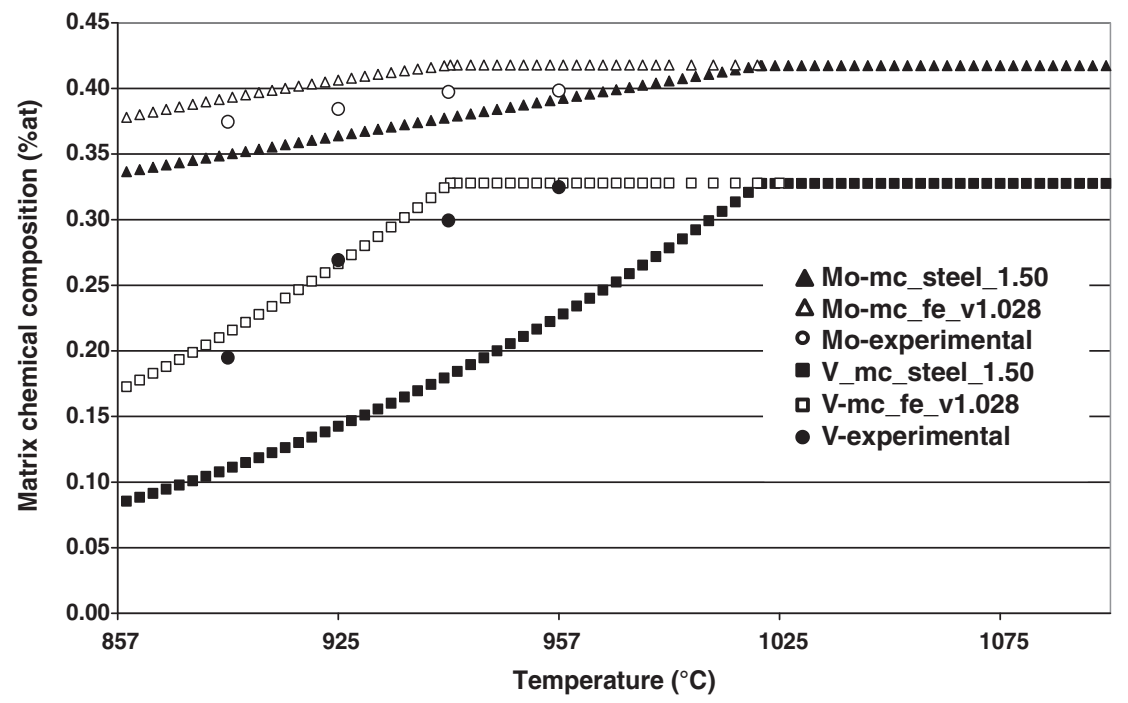

Fig. 7. Comparison between computed and experimental molybdenum and vanadium matrix contents in MoV-alloyed steel.

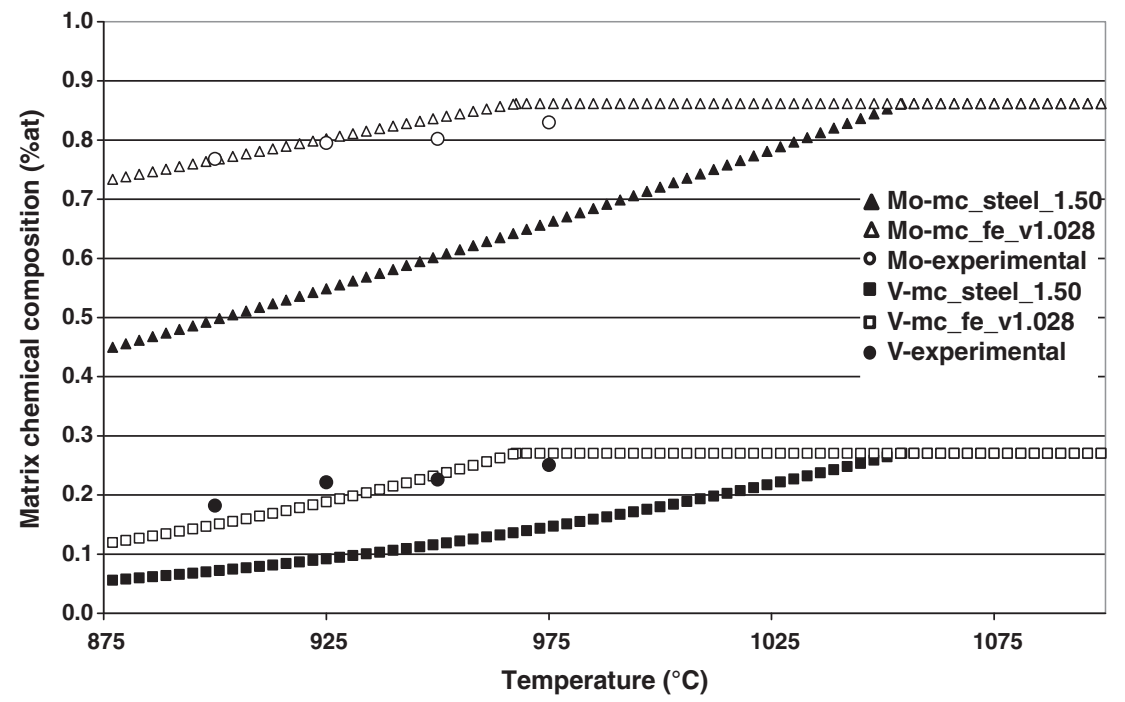

Fig. 8. Comparison between computed and experimental molybdenum and vanadium matrix contents in MoMoV-alloyed steel.

Table 7

Molybdenum content (at.\%) calculated using different versions of the databases at the studied temperatures.

\begin{tabular}{lllllll}
\hline & & $900\left({ }^{\circ} \mathrm{C}\right)$ & $925\left({ }^{\circ} \mathrm{C}\right)$ & $950\left({ }^{\circ} \mathrm{C}\right)$ & $975\left({ }^{\circ} \mathrm{C}\right)$ & $1000\left({ }^{\circ} \mathrm{C}\right)$ \\
\hline MoV & mc_steel_1.50 & 12.6 & 12.0 & 11.4 & 10.8 & 10.3 \\
& m_fe_v1.028 & 9.3 & 8.1 & 3.1 & 3.6 & 35.9 \\
MoMoV & m__steel_1.50 & 36.8 & 18.7 & 17.9 & - & 35.6 \\
& m__fe_v1.028 & 19.4 & 18.7 & - & - \\
\hline
\end{tabular}

the same subsystem were also studied. Table 8 lists the composition (atomic percent) of these steels, which were slightly modified with respect to the standard AISI H11 hot-work tool steel [11-14].

After extraction, the crystallographic structures of the precipitates were determined by XRD [11] for the three steels at $970{ }^{\circ} \mathrm{C}$. The results show that the variations in the carbides' compositions, with increasing Mo-content in the matrix, were the same as those found in the steels shown in Table 2, which contain MC cubic carbides but no $\mathrm{M}_{2} \mathrm{C}$ or $\mathrm{M}_{6} \mathrm{C}$ carbides. In the NiW steels, molybdenum is partially substituted by tungsten, which is very similar to molybdenum in terms of its chemical properties.

The experimental cristallographic structures were compared with the results computed for the mc_steel_1.50 database and the upgraded mc_fe_v1.028 database. These results are presented in Table 9. For the three steels, the crystallographic structures of the carbides calculated with the improved database are in good agreement with experimental results, and predict the precipitation of MC carbides. 


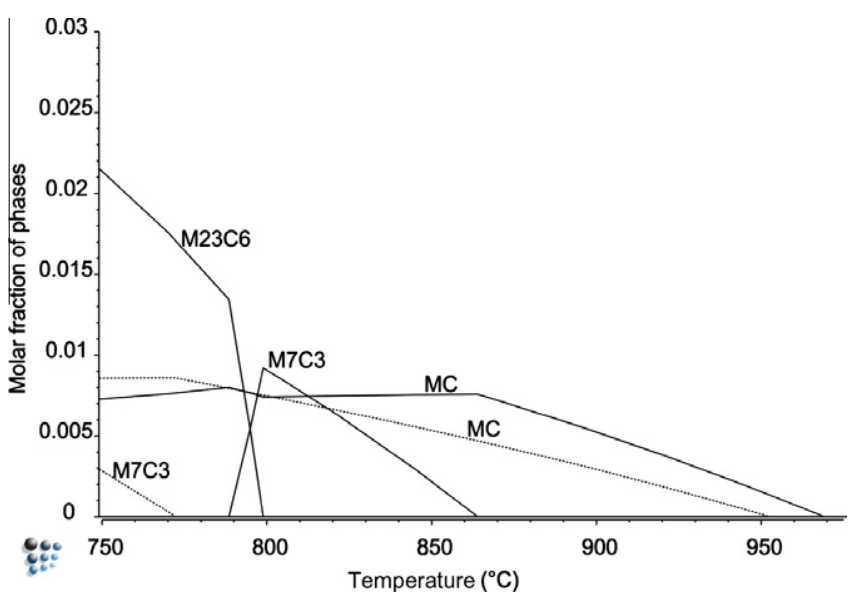

Fig. 9. Thermodynamic equilibrium phase fractions as a function of temperature, in MoV (dashed lines) and MoMoV (solid lines) steels, computed for mc_fe_v1.028.

Table 8

Chemical composition of the steels used for validation (at.\%).

\begin{tabular}{lllllllll}
\hline & $\mathrm{C}$ & $\mathrm{Si}$ & $\mathrm{Mn}$ & $\mathrm{Ni}$ & $\mathrm{Cr}$ & $\mathrm{Mo}$ & $\mathrm{V}$ & $\mathrm{W}$ \\
\hline Mo-alloyed & 1.50 & 0.55 & 0.36 & 0.08 & 5.41 & 1.05 & 0.50 & - \\
NiMo-alloyed & 1.50 & 0.55 & 0.35 & 1.72 & 5.50 & 1.05 & 0.51 & - \\
NiW-alloyed & 1.65 & 0.57 & 0.36 & 1.75 & 5.62 & 0.71 & 0.51 & 0.50
\end{tabular}

Table 9

Comparison between simulated and experimental results for the crystallographic structures of carbides.

\begin{tabular}{llll}
\hline & mc_steel_1.50 & mc_fe_v1.028 & Experimental \\
\hline Mo-alloyed & $\mathrm{M}_{2} \mathrm{C}$ & $\mathrm{MC}$ & $\mathrm{MC}$ \\
NiMo-alloyed & $\mathrm{M}_{2} \mathrm{C}$ & $\mathrm{MC}$ & $\mathrm{MC}$ \\
NiW-alloyed & $\mathrm{M}_{2} \mathrm{C}$ & $\mathrm{MC}$ & $\mathrm{MC}$
\end{tabular}

\section{Conclusions}

This study presents carbide and matrix content data recorded during austenitization. Carbide precipitation has been investigated for two different steels containing vanadium and molybdenum. The carbide solvus temperature, crystallographic structure, and chemical composition of the carbides, and the chemical composition variations of the matrix are now available for these two alloys.

- With the exception of orthorhombic $\mathrm{Cr}_{7} \mathrm{C}_{3}$ in MoMoValloyed steel at $900^{\circ} \mathrm{C}$, only face-centered cubic carbides were observed: $\mathrm{V}_{4} \mathrm{C}_{3}$ in the $\mathrm{MoV}$, and $\mathrm{MoC}_{0.5}$ in the MoMoV-alloyed steels. Significant molybdenum solubility was observed in the FCC carbides.

- On the basis of these experiments, the thermodynamic MatCalc steel database model parameters were optimized for the $\mathrm{Fe}-\mathrm{Cr}-\mathrm{Mo}-\mathrm{V}-\mathrm{C}$ system, resulting in improved phase equilibria predictions for the studied steel grades, as well as for modified hot-work tool steels AISI H11.

The experimental-approach presented in this paper, which makes use of separate matrix composition and precipitate chemistry quantifications is likely to be very useful for the study of precipitation variations in steels.
If applied to other industrial steels or experimental grades, this could be a promising technique for the acquisition of data needed for the improvement of thermodynamic databases corresponding to a wide range of chemical systems.

Finally, it is expected that a similar approach could be used to adapt this method to the study of other alloys (superalloys, aluminum, magnesium)

\section{References}

[1] Q. Li, Modeling the microstructure-mechanical property relationship for a $12 \mathrm{Cr}-2 \mathrm{~W}-\mathrm{V}-\mathrm{Mo}-\mathrm{Ni}$ power plant steel, Materials Science and Engineering A 361 (2003) 385-391.

[2] P.W. Hochanadel, C.V. Robino, G.R. Edwards, M.J. Cieslak, Heat treatment of investment cast $\mathrm{PH} 13-8$ stainless steel, Metallurgical and Materials Transactions A 25 (1994) 789-798.

[3] T. Antretter, F.D. Fischer, Critical shapes and arrangements of carbides in highspeed tool steels, Materials Science and Enginnering A 237 (1997) 6-11.

[4] R. Levêque, Traitements thermiques dans la masse des aciers à outils, Techniques de l'Ingénieur, 2002.

[5] F.B. Pickering, Physical Metallurgy and the Design of Steels, Applied Science Publishers, 1978.

[6] F. Meurling, A. Melander, M. Tidesten, L. Westin, Influence of carbide and inclusion contents on the fatigue properties of high-speed steels and tool steels, International Journal of Fatigue 23 (2001) 215-224.

[7] K. Shiozawa, Y. Morii, S. Nishino, L. Lu, Subsurface crack initiation and propagation mechanism in high-strength steel in a very high cycle fatigue regime, International Journal of Fatigue 28 (2006) 1521-1532.

[8] C.R. Sohar, A. Betzwar-Kotas, C. Gierl, B. Weiss, H. Danninger, Fractographic evaluation of gigacycle fatigue crack nucleation and propagation of a high $\mathrm{Cr}$ alloyed cold work tool steel, International Journal of Fatigue 30 (2008) 21912199.

[9] J.T. Tchuindjang, L. Lecomte-Beckers, Fractography survey on high cycle fatigue failure : Crack origin characterization and correlations between mechanical tests and microstructures in Fe-C-Cr-Mo-X alloys, International Journal of Fatigue 29 (2007) 713-728.

[10] F. Meurling A. Melander, M. Tidesten, L. Westin, Influence of carbide and inclusions contents on the fatigue properties of high speed steels and tool steels, International Journal of Fatigue 23 (2001) 215-224.

[11] P. Michaud, D. Delagnes, P. Lamesle, M.H. Mathon, C. Levaillant, The effect of addition of alloying elements on carbide precipitation and mechanical properties in 5\% chromium martensitic steels, Acta Materialia 55 (2007) $4877-4889$.

[12] K.B. Lee, H.R. Yang, H. Know, Effects of alloying additions and austenitizing treatments on secondary hardening and fracture behavior for martensitic steels containing both Mo and W, Metallurgical and Materials Transactions A 32 (2001) 1659-1670.

[13] J. Lu, D.G. Ivey, H. Henein, J.B. Wiskel, O. Omotoso, Extraction and characterization of nano-precipitates in microalloyed steels, in: 7th International Pipeline Conference, Canada, 2008.

[14] S. Mauriès, P. Michaud, D. Delagnes, P. Lamesle, E. Kozeschnik, Characterization and simulation of carbide precipitation during tempering of low silicon AISI H11 hot-work tool steel, in: 1st International Symposium on Steel Science 2007 (Kyoto, Japan), pp. 175-178.

[15] D. Delagnes, F. Pettinari-Sturmel, M.H. Mathon, R. Danoix, F. Danoix, C. Bellot, P. Lamesle, A. Grellier, Cementite-free martensitic steels: a new route to develop high strength/high toughness grades by modifying the conventional precipitation sequence during tempering, Acta Materialia 60 (2012) 58775888

[16] E. Kozeschnik, <http://www.matcalc.tuwien.ac.at> (accessed 29.10.12), current MatCalc version is 5.51.007.

[17] J. Epp, H. Surm, O. Kessler, T. Hirsch, In-situ X-ray phase analysis and computer simulation of carbide dissolution of ball bearing steel at different austenitizing temperatures, Acta Materialia 55 (2007) 5959-5967.

[18] K.E. Burke, Metallography 8 (1975) 473-488.

[19] M.M. Serna, J.L. Rossi, MC complex carbide in AISI M2 high-speed steel, Materials Letters 63 (2009) 691-693.

[20] Y.K. Oh, G.S. Kim, J.E. Indacochea, Creep rupture behavior due to the molybdenum rich $\mathrm{M}_{6} \mathrm{C}$ carbide in $1 \mathrm{Cr}-1 \mathrm{Mo}-0.25 \mathrm{~V}$ bainitic steel weldment, Scripta Materialia 41 (1999) 7-12.

[21] D.W. Hetzner, W.V. Geertruyden, Crystallography and metallography of carbides in high alloy steels, Materials Characterization 59 (2008) 825-841.

[22] D. Peidao, S. Gongqi, Z. Shouze, A scanning electron microscopy study of carbides in high-speed steels, Materials Characterization 29 (1992) 15-24.

[23] J.H. Jang, C.-H. Lee, Y.-U. Heo, D.-W. Suh, Stability of (Ti, M)C (M = Nb, V, Mo and W) carbide in steels using first-principles calculations, Acta Materialia 60 (2012) 208-217.

[24] R. Radis, E. Kozeschnik, Concurrent precipitation of AlN and VN in microalloyed steel, Steel Research International 81 (2010) 681-685. 